$\S=-1$

\title{
The Factors Affecting Behaviour Based Safety (BBS) Implementation in Oil and Gas Industry
}

\author{
Amanda Antonio Galis*, Norfashiha Hashim , Faridah Ismail \& Norazian Mohd Yusuwan \\ Faculty of Architecture, Planning and Surveying, Universiti Teknologi MARA, Selangor, Malaysia \\ *Corresponding author E-mail: amandaclare93@gmail.com
}

\begin{abstract}
The application of Behaviour-Based Safety (BBS) in the oil and gas industry is facing a severe challenge that safety performance may decline when BBS intervention is removed, due to the dynamic and transitory nature of working area and workforce. This research investigates the factors affecting the implementation of Behaviour-Based Safety (BBS) approach in Oil and Gas Industry. Seven oil and gas companies practicing BBS had been chosen for case study. These companies has been implementing BBS as part of the safety exercise from 2 to 20 years. The findings show that implementation of BBS started by the request from the client. Seven challenges of implementation BBS emerged during the interview that is data management, top management commitment, employee acceptance towards program, organizational safety culture and financial barrier. While, the factor that influences the implementation of BBS is the organization commitment, top management level, training and understanding of workers toward BBS are the factors that affect the implementation of BBS in oil and gas industries.
\end{abstract}

Keywords: Behaviour-Based Safety; Safety; Oil and Gas Industry.

\section{Introduction}

Behaviour based safety (BBS) is an approach associated with safety management system towards improvements of safety and health performances. BBS process effective in raising the level of behaviour and safety of workers as an alternative to reduce accidents and injuries in the industry. In the Oil and Gas industry, it may be more challenging to achieve persistent quality in behaviour-based safety results as the dynamics and transitory of works in nature. Although many factors may affect the final outcome or results of behaviour-based safety approach, but this difficulty largely attributed to the strategy and their process of implementation.

A portion of the present-day form of BBS appears to vary from the existing structures and practice, which would have included various other things [1]. Some companies have implemented in-house version of Behaviour-Based Safety (BBS) programs. To name a few are programs such as STOP, ASA, SOC and many others. These programs however have been driven by the Key Performance Indicators (KPI) which results them to suffer from numbercrunching instead of prioritizing on quality execution and the effectiveness of the program. A number of BBS consultant have tried to implement their respective copyright BBS programs there and there has been different successes [2]. The effectiveness of behavioural safety observation and feedback programmes is dependent upon effective implementation. The component involved in the implementation steps of BBS approach differs among researchers.

Despite the successful of implementations reported in the previous studies, present behaviour-based safety approach deals with a critical difficulty in achieving persistent and quality effects. There are many factors that could affect the implementation of BBS such as level of commitment [3], leadership which according to
McSween [4] is one of the main factor contributingto the BBS process, training provided, lack of action plan as well as failure to teach BBS principle to all workers, etc[5][6][7]. Therefore the aim of this paper is to establish the factors that influence BehaviourBased Safety system implementation in Malaysia oil and gas industry.

This paper is organized as follows. In section 2, the methodology of data collection and the results of in this paper are presented in section 3. Finally, our work of this paper is summarized in the last section.

\section{Methodology}

The overall aim of this study is to evaluate the factors that contribute to the implementation of BBS program in the industry. The outcome of the preliminary study on Safety and Health related practitioner resulted in the facts that BBS approach has been applied in the oil and gas industry in Malaysia. Hence, this leads to the choice of five safety officer/project managers from oil and gas company that has implement the BBS approach in their company. The method used for the data collection is by conducting interviews.

Seven interviewees were selected from five different oil and gas companies in Sarawak. All seven interviewees are Safety Officer in their respective company and the questions solicits from the implementation of BBS approach in their company, the challenges of BBS implementation in their company and the factors that affected the implementation of BBS in the oil and gas industry. Interviewee 1 works as a safety officer in Company 1 (C1) which is nation's sole liquefied natural gas (LNG) export gateway and it is noted as currently one of the largest LNG export terminal in the world. Company 1 (C1) is established in 1996. Company 1 (C1) is committed to creating a safe and secure working environment 
that protects the health and wellbeing of the employees. The company never compromised on the safety aspect and all workers are required to adhere to the security and safety policies. The company had implemented BBS for the past 20 years.

Interviewee 2 works as a Safety officer in Company 2 (C2) is an active Oil and Gas services contractor in Sarawak, Malaysia. Company 2 was established in 2001. Company 2 relentlessly pursue excellence in HSSE practises and proactively involves its employees, subcontractor, management and clients. The company had implemented BBS for 6 month.

Interviewee 3 works in Company 3 (C3) as a Safety officer is an Oil and Gas services contractor in Sarawak, Malaysia. Company 3 is established in 2000. The company HSSE objective is to work closely with clients to comply with Contractual Performance Evaluation and other requirements as well as to inculcate proactive HSE Culture by cascading Back to Basic Program and Behaviour Base Safety. The company had implement BBS for 3 years. Interviewee 4 works as Safety Officer in Company 4 (C4) main activities focused on Supply, Engineering, Services and Maintenance. Company 4 is established in 2015. Company 4 are PETRONAS registered License Company and also DOSH registered and approved on safety and health policy, compliance to workshop facilities and technical staff. The company caters for Oil $\&$ Gas, Petrochemical and General Industries. The company had implement BBS for 3 month.

Interviewee 5 works in Company 5 (C5) as Safety Officer is a provider of integrated services to the oil and gas industry in Malaysia. Company 5 is established in 1984. C5 have received award for Safety and Environment achievements, safety excellence, zero lost time incidents and good safety record. The company had implemented BBS for 4 years.

Interviewee 6 works in Company 6 (C6) as Safety Officer is provider of integrated services to the oil and gas industry in Malaysia. Company 6 is established in 1984. C6 have received award for Safety and Environment achievements, safety excellence, zero lost time incidents and good safety record. The company had implement BBS for 4 years.

Interviewee 7 works in Company 7 (C7) as Safety Officer in company that specialised product and services in the oil and gas industry. This company was establised $\mathrm{h}$ in 1990. The company had implement BBS for 2 years.

Table 1: Company involved and Interviewee Details

\begin{tabular}{|c|l|l|l|l|l|}
\hline Company & Designation & $\begin{array}{l}\text { Work Ex- } \\
\text { perience }\end{array}$ & Gender & $\begin{array}{l}\text { Interview } \\
\text { Duration }\end{array}$ \\
\hline $\begin{array}{c}\text { Company } \\
\text { Company } \\
2\end{array}$ & $\begin{array}{l}\text { Safety and } \\
\text { Health Of- } \\
\text { ficer }\end{array}$ & $\begin{array}{l}\text { Safety and } \\
\text { Health Of- } \\
\text { ficer }\end{array}$ & years & Male & $\begin{array}{l}1 \text { hour } 30 \\
\text { minutes }\end{array}$ \\
\hline $\begin{array}{c}\text { Company } \\
3\end{array}$ & $\begin{array}{l}\text { Safety and } \\
\text { Health Of- } \\
\text { ficer }\end{array}$ & 4 years & Male & 1 hour \\
\hline $\begin{array}{c}\text { Company } \\
4\end{array}$ & $\begin{array}{l}\text { Safety and } \\
\text { Health Of- } \\
\text { ficer }\end{array}$ & 3 years & Female & 2 hours \\
\hline $\begin{array}{c}\text { Company } \\
5\end{array}$ & $\begin{array}{l}\text { Safety and } \\
\text { Health Of- } \\
\text { ficer }\end{array}$ & 4 years & Male & 1 hour \\
\hline $\begin{array}{l}\text { Company } \\
\mathbf{7}\end{array}$ & $\begin{array}{l}\text { Safety and } \\
\text { Health Of- } \\
\text { ficer }\end{array}$ & $\begin{array}{l}\text { Safety and } \\
\text { Health Of- } \\
\text { ficer }\end{array}$ & 7 years & Male & 1 hour \\
\hline Company & & Female & 2 hours \\
\hline
\end{tabular}

\section{Results and Discussion}

This section shows the findings which highlight the aim of the research to determine the factor affecting BBS implementation in oil and gas industry. This section will discuss on the level of im- plementation BBS in the company, the challenges of implementing BBS and the factors influencing BBS.

The establishment period of the company as well as the company stability affects the level of BBS implementation in the company. A company that was established longer tend to have practise BBS system in their company longer due to the fact that they had been around longer. This also shows that BBS had been exposed and implemented in oil and gas industry in Sarawak for a while, at least 20 years back which can be proved with Company 1 that had practise this safety system for that period.

Table 2: Implementation period in the company

\begin{tabular}{|c|c|}
\hline Company & $\begin{array}{c}\text { Duration of BBS implemen- } \\
\text { tation }\end{array}$ \\
\hline Company 1 & 20 years \\
\hline Company 2 & 6 month \\
\hline Company 3 & 3 month \\
\hline Company 4 & 2 years \\
\hline Company 5 & 3 years \\
\hline Company 6 & 4 years \\
\hline Company 7 & 2 years \\
\hline
\end{tabular}

Based on the interview done, all seven (7) of the oil and gas companies studied for this research implemented Behavioural-Based Safety in their organisation. Most of the companies have medium level of implementation with $57 \%$ of the company had implement this safety system between 1 to 5 years.

Only $14 \%$ of the companies in Sarawak had implemented BBS in their organisation for more than 5 years. One of the key reasons is some of the oil and gas companies in Sarawak are relatively new and they need to have a more stable operation first before taking major steps such as implementing Behaviour-Based Safety in their organisation.

The establishment period of the company as well as the company stability affects the level of BBS implementation in the company. A company that was established longer tend to have practise BBS system in their company longer due to the fact that they had been around longer. This also shows that BBS had been exposed and implemented in the oil and gas industry in Sarawak for a while, at least 20 years back which can be proved with Company 1 that had practised this safety system for that period.

Table 3: Level of Acceptance of BBS Implementation

\begin{tabular}{|l|c|}
\hline Company & $\begin{array}{l}\text { Workers level of acceptance of BBS ap- } \\
\text { proach in the company }\end{array}$ \\
\hline Company 1 & Good \\
\hline Company 2 & Medium \\
\hline Company 3 & Good \\
\hline Company 4 & Good \\
\hline Company 5 & Good \\
\hline Company 6 & Bad \\
\hline Company 7 & Good \\
\hline
\end{tabular}

A significant number of oil and gas companies in Sarawak workers have a good level of acceptance towards BBS system applied in the company.

The levels of acceptance are not affected by the duration of BBS practised in the company. This can be proved based on the case study on company 2 and company 6 . Based on the interview conducted with Safety and Health Officer of both the company, company 6 had implemented $n$ practise BBS in their organisation for a longer period than company 2 but the workers level of acceptance on BBS in company 2 is better than company 6 .

There are various reasons that could influence the workers acceptance level in the company such as the company safety culture, the employees' attitude towards changes, leadership and many more. These will be explained further in challenges of implementing BBS and factors affecting BBS implementation in the industry. Based on the interview done, there are seven (7) challenges of implementing Behavioural-Based Safety (BBS) that are identified. These themes emerge based on the interview done with seven (7) safety officers from seven (7) different oil and gas companies. 
Table 4: Challenges of BBS Implementation

\begin{tabular}{|c|c|c|c|}
\hline Challenges & Description & $\begin{array}{c}\text { No. of } \\
\text { Statement }\end{array}$ & $\%$ \\
\hline $\begin{array}{l}\text { Data Management } \\
\text { Barrier }\end{array}$ & $\begin{array}{l}\text { The company data manage- } \\
\text { ment level. Whether the com- } \\
\text { pany data management system } \\
\text { can support the data on BBS } \\
\text { process }\end{array}$ & 4 & 17.5 \\
\hline $\begin{array}{l}\text { Superior under- } \\
\text { standing of BBS } \\
\text { benefit }\end{array}$ & $\begin{array}{l}\text { The superior or top manage- } \\
\text { ment understanding of BBS } \\
\text { approach. Whether they know } \\
\text { the benefit of implementing } \\
\text { BBS in the organisation }\end{array}$ & 4 & 17.5 \\
\hline $\begin{array}{l}\text { Employees atti- } \\
\text { tude towards } \\
\text { change }\end{array}$ & $\begin{array}{l}\text { The employees' attitude to- } \\
\text { wards the changes in the com- } \\
\text { pany. Whether the employees } \\
\text { will have any protest if BBS } \\
\text { implemented in the company. }\end{array}$ & 1 & 4 \\
\hline $\begin{array}{l}\text { Top management } \\
\text { awareness of BBS } \\
\text { approach }\end{array}$ & $\begin{array}{l}\text { Whether the top management } \\
\text { knew about Behaviour-Based } \\
\text { Safety. }\end{array}$ & 3 & 13 \\
\hline $\begin{array}{l}\text { Company safety } \\
\text { culture }\end{array}$ & $\begin{array}{l}\text { The organisation level of safe- } \\
\text { ty culture }\end{array}$ & 1 & 4 \\
\hline Internal Conflict & $\begin{array}{l}\text { The emergence of internal } \\
\text { conflict for cases when there } \\
\text { are changes such as BBS im- } \\
\text { plementation. }\end{array}$ & 3 & 13 \\
\hline Financial Issue & $\begin{array}{l}\text { Whether the company has any } \\
\text { financial issue that prevents } \\
\text { the implementation of BBS. }\end{array}$ & 7 & 31 \\
\hline & TOTAL & 23 & 100 \\
\hline
\end{tabular}

The most significant challenges are financial issue at $31 \%$ followed by data management barrier and superior understanding of BBS benefit at $17.5 \%$ for both challenges.

The major challenge that affects the implementation of Behavioural-Based Safety in the industry is financial. Safety in general costs a fortune as there are many processes involved to maintain safety such as awareness program, training, seminars and many other safety activities. Aside from that, safety costing also includes Personal Protective Equipment (PPE), signage at workplace and other.

However, safety in workplace is a priority in oil and gas industries due its nature of work, effective safety approach are important in the industry despite its high cost. Amongst significant statement made by safety officers during the interview to support this point:

"I think one of the challenges of implementing BBS in the industry is financial issue. There are various cost needed to provide safety in the organisation such as PPE, seminars and many more. Implementing BBS in the organisation definitely cost a fortune as the employees need to go for trainings, and there is also consultant fees and many other cost."

"Financial is one of the challenges on BBS implementation. BBS have been practised in this company for a while but there is still conflict that arises due to the high cost of safety in the company. Although it is well known that safety in general is expensive, we (Safety and Health Department) are always urged to try and decrease the cost."

Another challenge that affects BBS implementation in the industry is data management barrier at $17.5 \%$. Behavioural-Based Safety processes usually starts with observation where observer filled in form of any unsafe behaviour. The form collected could be hundreds or thousands which proved to be challenging to process without good data management system. The presence of good data management system in a company that implement BBS is crucial to ensure the effectiveness Behavioural-Based Safety practised in the company. Statement that highlight this point:

"I believe that good data management system in the company is important if a company want to have effective BBS. Without the presence of good data management system, the data could not or would be hard to be recorded, keep track as well as analyse. The absence of excellent data management system would be challenging"
Superior understanding on Behavioural-Based Safety benefit is important to implement this safety system in the company. Without the support of the superior, Behaviour-Based Safety (BBS) could not be implemented in the company. Only when the top management understands the concept of BBS as well as are convinced that BBS implementation would be beneficial to the company can the BBS be successfully implemented. This is because superior or top management are the ones who make the major decision in the company.

"The challenge that affects BBS implementation in the company is the superior understanding on BBS benefit. The top management support has a huge impact on the workers. Only by understanding and believing that BBS can be beneficial to the company safety performance could the superior convince the workers on practising BBS."

Employee attitude towards change is one of the challenges of implementing BBS in oil and gas industry. Implementing BBS in a company is a major change in an organisation. The employees would have to attend seminar, undergoes training and observe unsafe behaviour on top of doing what he or she had been doing now. These could be a turn-off for the employees as they think it is inconvenient. They have to adapt to the changes as well when they most probably are comfortable with the current state of work. As employees are the backbone of a company and the organisation could not force someone to accept change readily, employees attitude towards change are one of the challenges of BBS implementation.

One of the challenges of BBS implementation is top management awareness of BBS approach. Some of the top management are not exactly people in the oil and gas industry which makes them oblivious to the safety approach such as BBS. However, as these individuals have significant role in the company which makes them responsible as the decision maker for the company. In cases where the top management are not aware of the safety system, it could be challenging to convince them to implement BBS in the organisation.

Safety culture of an organisation contributes to the challenges of implementing BBS in oil and gas industry. A significant amount of oil and gas companies have good safety culture due to the importance of safety in this particular industry. However, there are a number of companies that do not have goods safety culture thus making it challenging to implement BBS in the company. It is difficult to convince a company who held no importance of safety in their organisation to implement this safety approach.

Internal conflict is another challenge of implementing BBS in the industry. Internal conflict usually occurs when there are various parties involved in making a decision. For cases like BBS implementation in oil and gas companies, this conflict could occur between department such as Health, Safety and Environment department with Financial Department due to issues such as the high cost involve for implementation to occur. Conflict could also arise between employees and top management or any other parties that are in the organisation and are affected by the changes.

For the factors affecting BBS implementation, six (6) themes were established from interviewees' perspective on the factors affecting BBS implementation. The table below shows the list of theme emerged.

Table 5: Factors Affecting BBS implementation

\begin{tabular}{|l|l|c|c|}
\hline \multicolumn{1}{|c|}{ Factors } & \multicolumn{1}{|c|}{ Description } & $\begin{array}{c}\text { No. of } \\
\text { Statement }\end{array}$ & $\%$ \\
\hline $\begin{array}{l}\text { Clients' Require- } \\
\text { ment }\end{array}$ & $\begin{array}{l}\text { Clients' request or demand } \\
\text { for the company to practice } \\
\text { BBS. }\end{array}$ & 4 & 24 \\
\hline Commitment level & $\begin{array}{l}\text { Employees' level of com- } \\
\text { mitment on BBS approach } \\
\text { applied by the company. }\end{array}$ & 3 & 17.5 \\
\hline $\begin{array}{l}\text { Superior Involve- } \\
\text { ment }\end{array}$ & $\begin{array}{l}\text { The top management in- } \\
\text { volvement the safety ap- }\end{array}$ & 3 & 17.5 \\
\hline
\end{tabular}




\begin{tabular}{|l|l|c|c|}
\hline & proach & & 17.5 \\
\hline Training & $\begin{array}{l}\text { The exposure of BBS to the } \\
\text { employees }\end{array}$ & 3 & 6 \\
\hline $\begin{array}{l}\text { Company Action } \\
\text { Plan }\end{array}$ & $\begin{array}{l}\text { Companies' plans to im- } \\
\text { prove BBS approach im- } \\
\text { plemented }\end{array}$ & 1 & 17.5 \\
\hline $\begin{array}{l}\text { Understanding of } \\
\text { BBS Principle }\end{array}$ & $\begin{array}{l}\text { Employees level of under- } \\
\text { standing on BBS approach. }\end{array}$ & 3 & 100 \\
\hline & TOTAL & 17 & 17 \\
\hline
\end{tabular}

The study showed that oil and gas companies in Sarawak had significant factors that affect the implementation of BBS in the industry. The interview indicates that the main factors affecting BBS implementation were clients' requirement at $24 \%$ followed by commitment level, superior involvement, training and understanding of BBS principle at $17.5 \%$ as well as company's action plan at $6 \%$.

One of the most significant factors affecting BBS implementation is clients' requirement. A huge number of oil and gas companies in Sarawak implement BBS due to request and demand of their client.

One of the problems encountered on BBS implementation is lack of commitment on the program. The reasons for such lack of commitment stem from the personnel perspective that does not believe the effectiveness of the safety approach. Furthermore, there are chances that the observer does not know how to discuss the observation. Among important statement made which support these factors were the following:

' $B B S$ is only implemented in this company due to the client re quest. This knowledge makes the employees think that BBS is implemented just to fulfil the client requirement and do not believe that the company is trying to improve safety thus making them less committed to the safety approach.'

'Some of the employees are illiterate which makes them have a hard time to fill in forms regarding safety thus making it hard for them to report any incidence of unsafe behaviour that they witness.'

Lack of leadership support is one of the most significant factors contributing to problems with BBS process. Leaders have to be the role model for the employees to encourage and increase employees' commitment on the safety approach. It is recommends that leaders need to take part in some visible safety-related activity every week. These would result in the subordinate following their leader steps. Significant statements made by interviewee that support this factor were:

'Most employees follow their superior's footsteps. When top management is present in an activity, the attendance for the activities would significantly increase compared to when there is no higherup presence.

One of the important elements that contribute to the success of BBS is adequate BBS training. Training program would be the first exposure to BBS for the workers. Training programs could result in a positive behaviour change amongst the participants Statement made by one of the participant that strengthen the factor were:

'Employees are required to attend BBS training once a year. The level of commitment and their knowledge in BBS brings in positive results which can be seen in the safety performance'

Most organization only prioritizes on the observation and does not focus on the goal of the approach which is to improve safety. It is essential for a company to have action plan to improve the BBS implemented to achieve quality effect.

Safety programs are often introduced in an organisation and to many, the new safety approaches is just another set of temporary procedures that will make the management look good instead of believing that the safety approach would be. This is the results that stem due to multiple safety programs applied without the employees understanding of the safety program.

\section{Conclusion}

Oil and gas industry nature of work is dangerous due to various reasons. Various safety approaches has been introduced worldwide to minimize and prevent injury and accident to occur in oil and gas industries. Behaviour-based safety is one of the widely known safety approach that could tackle the safety problem in oil and gas industry. However, not all organisations that implement this safety approach manage to improve their safety performance. Seven case studies had been done to study the level of implementation, challenges of BBS implementation and factors that affect the implementation of the BBS in oil and gas industry. It can be concluded that most company implement this safety approach due to requirement by clients as majority of them started implementing this safety approach due to the clients' request. The level of workers acceptance mostly affected by the period of the safety approach had been implemented in the company. In addition, findings also indicates that the factor that affects the implementation of BBS includes workers level of commitment, superior level of involvement, training provided, lack of action as well as the workers level of understanding of BBS principle. For the challenges of BBS implementation in the company, financial issues, and top management support appears to be a top barrier that hinders the BBS implementation. This maybe because most of the companies implemenedt BBS is by client's request.

This study formed a basis that can be used for analszing the factors that influences the BBS implementation in the company. This paper however is not a panacea for the evaluation of behaviour based safety; further work is required to sufficiently evaluate the industry. Limitations of this research need to be acknowledged. First, the relatively small sample sizes lead to a concern about generalization. Finally, it is possible that the results reported here may have been influenced to some extend in the analysis, due to reliance on data reported by a single, though well-informed source (respondent) in each company.

\section{Acknowledgement}

The authors wish to acknowledge the support from Universiti Teknologi MARA (Project Code: 600-RMI/DANA 5/3/LESTARI (71/2015)) for this research. Special thanks also go to the reviewers for their invaluable comments on this paper. Not forgetting that special gratitude is given to the industry practitioners who responded and contributed to the valuable input in completing the data collection.

\section{References}

[1] Greg, Z. (2015). Behaviour-Based Safety Program-Should They be Implemented. Occupational Health \& Safety. Retrieved from: https://ohsonline.com/Articles/2015/10/01/BBS-Programs.aspx

[2] Al Abdul Salam, A., Adivi, B. S. S., Al-Qallaf, Y., \& Pichery, L. (2013). Implementing Behavior Based Safety (BBS) Program in a Middle Eastern Work Environment: Lessons Learned. Society of Petroleum Engineers. doi:10.2118/163761-MS

[3] Ismail, F., Hashim, A. E., Zuriea, W., Ismail, W., Kamarudin, H., \& Baharom, Z. A. (2012). Behaviour based approach for quality and safety environment improvement: Malaysian experience in the oil and gas industry. Procedia-Social and Behavioral Sciences, 35, 586-594.

[4] McSween, T. (2013). Common Problems with Behavior-Based Safety Processes: Low Participation. Retrieved from: https://www.qualitysafetyedge.com/common-problems-withbehavior-based-safety-processes-low-participation.

[5] Wu, T.C., Chen, C.H., Li C.C., (2008). A correlation among safety leadership, safety culture and safety performance. Journal of loss prevention in the process industries. 21,307-318.

[6] Geller, E. S., \& Williams, J. H. (Eds.) (2001). Keys to behaviorbased safety from Safety Performance Solutions. Rockville, MD: ABS Consulting. 
[7] Frederick, J., \& Howe, S. (2001, February). The employee's perspective on behavioral safety. Paper presented at the ASSE Symposium, Behavioral Safety: The Next Step, Orlando, FL. 